\title{
On the 13th Floor
}

\author{
On the balcony of the thirteenth floor, \\ black cat hissing and growling in my arms, \\ a crow perches on the skyline and caws, \\ I tear apart and throw away my charms, \\ smash mirrors until I stand in a spray \\ of broken glass and wait for thunder, \\ while the crow casts an evil eye my way \\ and on the radio Stevie Wonder's \\ singing about seven years of bad luck \\ but I don't care, not even if the third \\ disaster leaves me blind or lightning struck, \\ anything to not have to speak the words, \\ to not have to take back the vows we swore \\ by saying: 'I don't love you anymore.'
}

Shoshanna Beale 